\title{
The Effect of Isolation on the Life-history Traits of Pseudosuccinea columella (Pulmonata: Lymnaeidae)
}

\author{
Alfredo Gutiérrez ${ }^{+}$, Gloria Perera, Mary Yong, Lin Wong
}

Laboratorio de Malacología, Instituto “Pedro Kourí, Apartado 601, Marianao 13, La Habana, Cuba

A population of Pseudosuccinea columella was raised under laboratory conditions and its life tables were determined in isolated and paired snails. Isolated snails were significantly larger in shell size than paired snails from five weeks of age onward. Also, statistically significant differences were found for the number of eggs per mass per individual from week 5 to 9, isolated snails exhibiting the highest values. The intrinsic and finite rates of increase were greater in isolated than in paired snails. Either an inhibition of the reproductive output between individuals or the advantage of selfing may be the cause of the differences in this species, acting as a possible mechanism that increase the fitness of isolated snails.

Key words: Lymnaeidae - Pseudosuccinea columella - life history traits - isolation

Growth, survival and reproduction in the family Lymnaedae (Mollusca: Prosobranchia) have been widely studied. Snails of this taxon are known to be hermaphrodites and to reproduce both by selffertilization (selfing) and outcrossing. The proportion of selfing in natural populations of lymnaeid snails is to our knowledge unknown, but presumably more important in small populations and in stable environments.

Pseudosuccinea columella (Say 1817) is in importance the second intermediate host of the trematode Fasciola hepatica Linnaeus, 1758 in Cuba (Mauri 1981). As this parasite is the causal agent of fasciolosis, a disease that affects domestic animals as well as people, the study of its hosts' biology may help the control of its transmission.

Several studies have been published on the demography of lymnaeids (Vergani 1955, DeWitt \& Sloan 1958, Malek \& Chrosciechowski 1964, Martinez \& Miranda 1968, Morales et al. 1983, 1985, 1986, Pino et al. 1986). Regarding Cuban populations, some studies compare the biology of $P$. columella with that of Fossaria cubensis, the most important intermediate host of $F$. hepatica, (Ferrer et al. 1988, 1989) and other works emphasize on the biology and demography of $F$. cubensis (Yong et al. 1996). However, most of the previous papers based their results on groups of snails, where competition for available resources takes place. Furthermore, for snails experimentally raised in

\footnotetext{
${ }^{+}$Corresponding author. Fax: 53-7-246051. E-mail: alfredo@ipk.sld.cu

Received 16 June 2000

Accepted 21 February 2001
}

groups, sometimes deviations of expected results have been observed as populations grow older and their size is reduced due to the death of some snails. The present research aims to report on the life-history traits of $P$. columella under the effect of complete isolation, fertilization being accomplished only by selfing; compared to snails raised together with a conspecific partner, allowed to both crossand self-fertilization and where intra-specific communication takes place.

\section{MATERIALS AND METHODS}

The parental snails for the study were collected from a temporary pond in La Palma municipality, Pinar del Rio Province, located west of the island of Cuba. The specimens were removed from their habitat with a hand sieve, sampling the bottom as well as the vegetation present on the shores, then taken to the laboratory on wet filter paper inside plastic cases. Upon arrival to the laboratory all snails (60 in total) were placed in a petri dish (PYREX® USA, $88 \mathrm{ml}$ of water volume) for 15 days with a pool of algae of the genera Lyngbya, Leptolyngbya, Phormidium and Schimidleinema as the food source. After seven days a number of egg masses was removed and placed into another similar dish, then 40 newly hatched snails were randomly selected for the life tables experiment. Twenty newly-hatched individuals (isolated snails) were raised in complete isolation (one snail per dish) and the other 20 (paired snails) were grown in pairs (two snails per dish).

The age zero of the experiment was considered as the week when all 40 newly hatched snails emerged from their egg masses. All mollusks were raised using the petri dishes and pool of algae mentioned above as container and food source respectively with calcium/nitrate-enriched mud as sub- 
strate, which has been demonstrated to be highly successful in terms of reproduction and growth for the culture of lymnaeids (Sanchez et al. 1995). Snails were moved once a week into a new dish and in all cases excess of uneaten algae was observed during the whole experiment. Also, no snail was ever seen attached to the dish cover, an event observed when some snails are kept in the same dish during a relatively long period of time, the cause being the lack of oxygen in the air, which is necessary for all pulmonates. These two evidences indicate that neither food nor space was a limiting factor for any of the groups in this experiment. Laboratory conditions remained constant with a photoperiod of $12 \mathrm{~h}$ and a temperature of $26^{\circ} \mathrm{C}$. Egg masses were removed from the mud and eggs were counted upon a weekly basis under a stereoscope (Olympus Optical Co. Ltd), recording the number of living and dead snails as well as the total number of eggs and viable eggs. Eggs laid each week were counted and placed in separated petri dishes until hatching. Viable eggs were considered as those that hatched within a period of 15 days. The size of each snail was also measured every week with a caliper ( $0.1 \mathrm{~mm}$ precision) and weekly shell size averages were used for plotting the growth curves. The following life-tables were calculated using the software TABVID ${ }^{\circledR}$ (version 2.0) developed by the Laboratory of Malacology (@1996 of IPK): survival probability (lx), fecundity rate $(\mathrm{mx})$, hatching rate $(\mathrm{hx})$, net reproduction rate (Ro), mean generation time $(\mathrm{T})$, finite rate of increase $(\lambda)$ and intrinsic rate of increase (r), calculations were made as proposed by Stearns (1992). The hatching rate was calculated as the number of viable eggs divided by the total number of eggs.

Mean shell sizes were compared between groups by a Student-T test. The Kendall's coefficient of concordance (Kendall 1975) was used in order to statistically measure the relatedness between survival curves of isolated and paired snails. To compare values of $\mathrm{mx}$, number of eggs per mass per individual and number of egg masses per individual between groups, a Mann-Whitney-U test was performed. For paired snails, the number of egg and egg masses was divided by 2 to make them relative to one snail. Differences between population rates of natural increase were not statistically tested for significance since each group rendered only one value and the necessary replication was logistically impossible.

\section{RESULTS}

Isolated snails exhibited higher shell sizes than individuals grown in pairs (Fig. 1A). Statistically significant differences were found at week 5 $(\mathrm{t}=-3.765, \mathrm{P}<0.001,14.4 \pm 0.58 \mathrm{~mm}$ and $13.4 \pm$ $0.68 \mathrm{~mm}$ in shell size for isolated and paired snails respectively) and onwards. The differences were even greater at week 10, when isolated and paired snails averaged $16.3 \pm 0.85 \mathrm{~mm}$ and $14.1 \pm 0.59$ $\mathrm{mm}$ in shell size respectively $(\mathrm{t}=-5.18, \mathrm{p}<0.001)$.

The life span of snails from both groups was the same (27 weeks) but the survival curves showed a different shape (Kendall's concordance coefficient $=0.02)($ Fig. 1B). The curve for isolated snails was step-like during the entire period, whereas paired snails exhibited a high survival at the beginning of their life range, with a quick decrease from week 9 to 13, becoming then stable and gradually decreasing.

Values of $m x$ also differed significantly between groups from week 5 to $9(\mathrm{U}=3.5, \mathrm{p}<0.001)$ (Fig. 1C). Both curves also exhibited a similar trend. Patterns of hx curves were not definite (Fig. 1D), although statistically significant differences were found for weeks 3 and $4(\mathrm{U}=12, \mathrm{p}<0.01)$, paired snails showing the highest values in both cases. Significant differences were also found for the number of eggs per mass $(U=5.00, p<0.001)$ from week 6 to 9 (Fig. 2B), isolated snails attaining the higher values. However, paired snails laid more egg masses than isolated snails (Fig. 2B), significant differences being obtained for weeks 3,4 , 6 and $11(\mathrm{U}=3, \mathrm{p}<0.01)$.

Regarding the population rates of natural increase, $r$ and $\lambda$ were higher for isolated snails than for paired snails (Table). The same differences were obtained for Ro and T.

\section{TABLE}

Age-independent life history traits of Pseudosuccinea columella snails raised individually (isolated snails) and in pairs (paired snails)

\begin{tabular}{lcccc}
\hline Group & Ro & $\mathrm{T}$ & $\lambda$ & $\mathrm{r}$ \\
\hline Isolated snails & 878.9 & 6.13 & 6.58 & 1.88 \\
Paired snails & 688.6 & 6.08 & 5.89 & 1.77 \\
\hline
\end{tabular}

Ro: net reproduction rate; T: mean generation time; $\lambda$ : finite rate of increase; $r$ : intrinsic rate of increase

\section{DISCUSSION}

Several studies on the life history traits of $\mathrm{Cu}$ ban populations of lymnaeid snails have been conducted; the majority under laboratory conditions (see Yong et al. 1996). However, in most of the information reviewed the authors do not take into account the effect of isolation on the reproduction and growth of the snails. In laboratory stocks of this species, some individuals become isolated due to the death of their partners and an increase of their reproduction has been observed (unpublished data). 
A

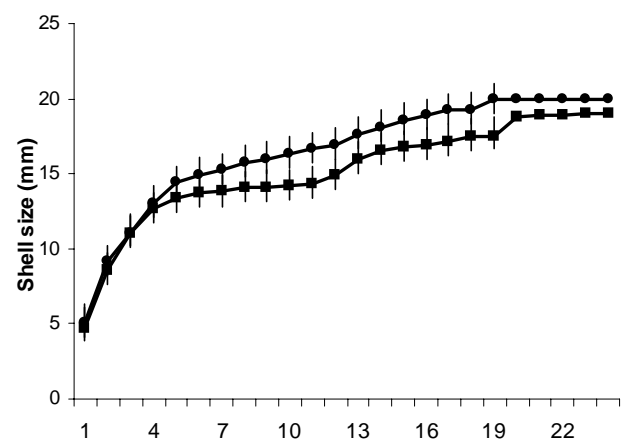

C

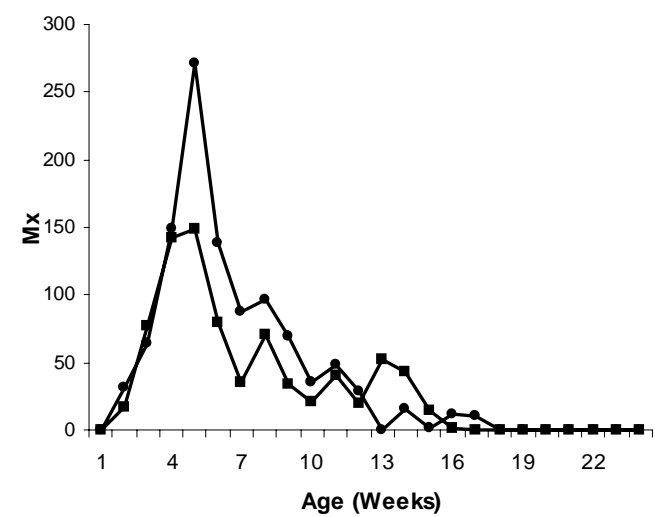

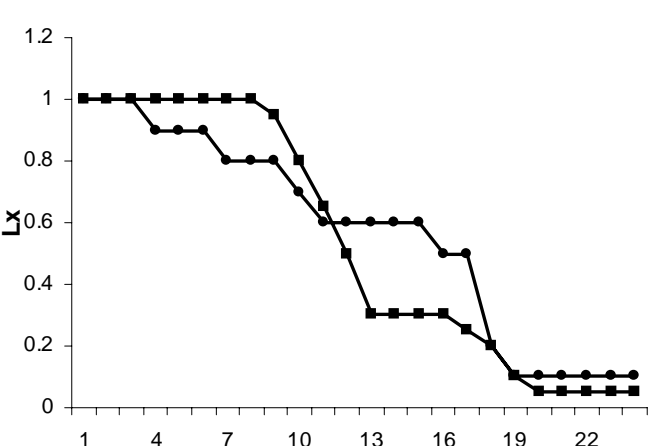

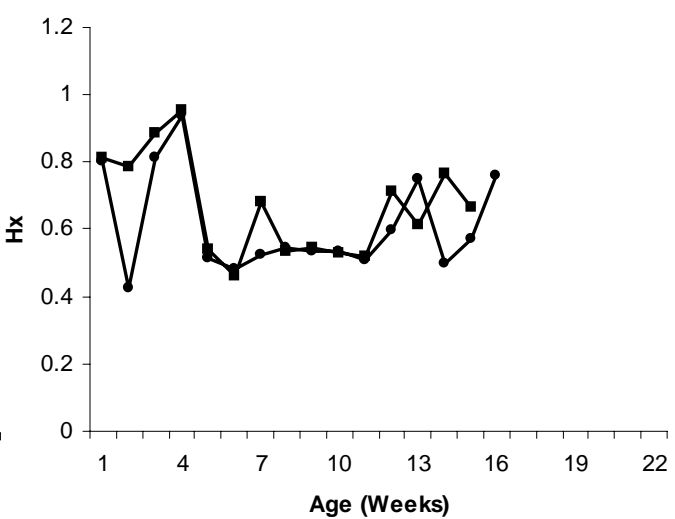

Fig. 1: life history traits for Pseudosuccinea columella snails grown in isolation $(\bullet)$ and in pairs $(\mathbf{\square})$. Vertical lines represent standard deviations. A: growth in shell size; B: survival probability; C: fecundity rate; D: hatching rate

All snails raised in pairs lasted longer than seven weeks (the first snail died during week 8). Besides, in only three pairs one of the partners died before the other previous to week 20 , all other snails either survived until week 22 (after which no reproduction was observed) or both partners died in the same week. The fact that the death of a partner might affect the mating system is accepted, however we do not consider that it significantly affected the life-history traits of the group since all deaths occurred when snails were either not reproducing at all or (in fewer cases) laying few eggs. Therefore, calculations still hold significant since all paired snails grew up actually in pairs pass their reproductive peak and just a few of them lost their partners when contribution to the population growth was not significant (Fig. 1C)

In this study we analyzed the alterations of the life tables in specimens of $P$. columella raised in isolation compared to those raised in pairs. It is evident that differences related to snail's reproduction, growth and survival do exist. Individuals grown in isolation showed a greater reproduction rate and shell growth than those grown in pairs. Since all snails were raised with excess of food and space to grow and reproduce likely that the observed differences are a consequence of intraspecific competition. Instead, the observed reduction of the number of eggs per mass and growth rate in paired snails seems to be due to either a chemical interaction between individuals or to a possible reproductive disadvantage of outcrossing. Either or both of the following processes could sustain the former statement: the releasing of an inhibitory substance into the water and/or a direct inhibition that may take place, for instance, during copulation. The relationship between water chemical composition and reproduction has been investigated by Nezlin (1997), who states that the ablation of the osphradium (a chemosensory organ) resulted in a significant increase of the egg laying activity in Lymnaea stagnalis. Osphradia are generally believed to be chemoreceptors, acting to test the composition of the incoming current (Hyman 1967).

The observed reduction of reproduction between partners may exist as a strategy in order to regulate the increase in numbers. This auto-regulation seems to be exerted on the number of eggs per mass, since the number of egg masses was 

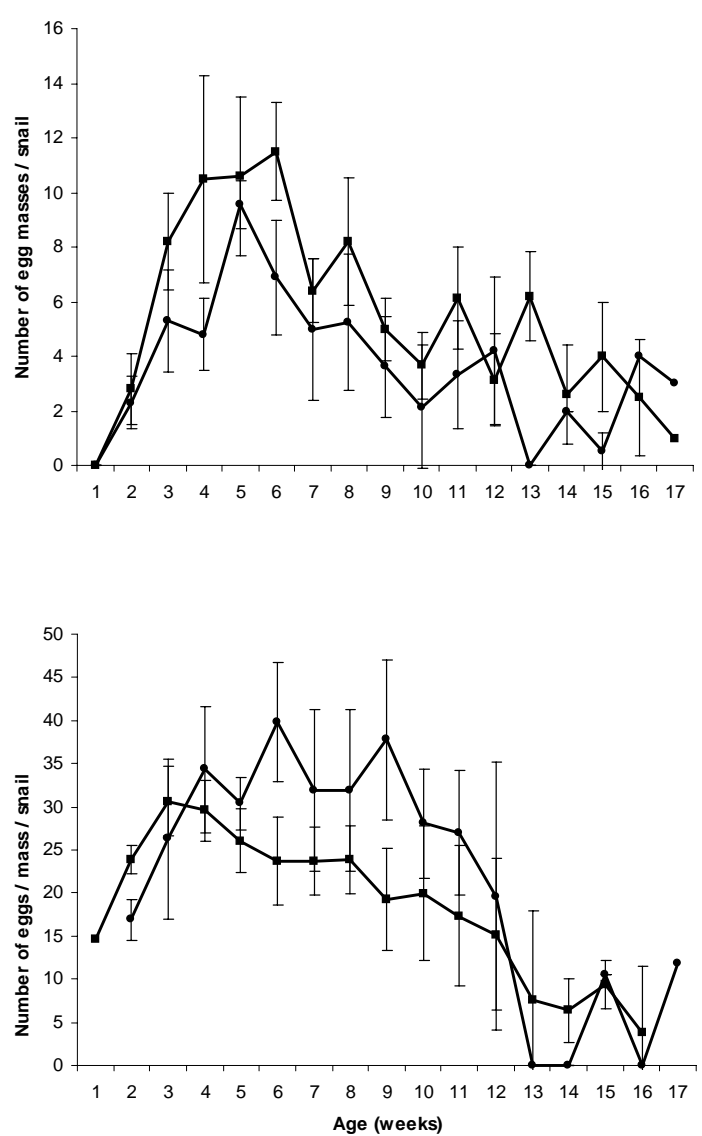

Fig. 2: number of eggs masses per snail (A) and number of egg per mass per snail (B) for Pseudosuccinea columella snails grown in isolation $(\bullet)$ and in pairs ( $)$. Vertical lines represent standard deviations.

higher for paired snails. Following this thought, as the population grows larger, the reducing effect would increment to avoid the negative consequences of crowding.

It does not seem plausible that the energy used by isolated snails to increase their reproductive output in terms of the number of eggs per mass, is utilized at expense of the body growth, because isolated individuals also exhibited a greater increment in shell size. This may suggest that, presumably, snails raised in isolation may have a stimulated feeding behavior compared to those raised in pairs, since growth and reproduction are antagonistically regulated within the snail. Consequently, the reduction of eggs production in paired snails might occur along with an inhibition of the feeding behavior. Furthermore, it is possible that this higher fecundity in individually grown snails goes in detriment of the egg viability, as shown by the differences in the number of viable eggs per individual (Fig. 1D).
It is noticeable that isolated snails of this species reproducing only by selfing have a greater Ro than paired snails, but since $\mathrm{T}$ is also greater in the former group, the differences for the rates of increase are no as high as those for the number of eggs per mass. DeWitt and Sloan (1958) observed similar effects of the isolation on this species for reproduction and growth; they attributed the differences between isolated and paired individuals to some unknown genetic mechanism. For $L$. stagnalis, De Visser et al. (1994) also observed that mating caused a reduction in the production of eggs. For the planorbid Biomphalaria glabrata however, Vianey-Liaud (1976) observed the opposite effect, reproduction and growth were more intense in paired than in isolated snails. Furthermore, some authors working on the genus Bulinus have pointed out that the usually lower fertility is one of the disadvantages of self-fertilization (Doums et al. 1994, Jarne \& Stadler 1995). For $B$. glabrata Vianey-Liaud (1998) states that after the use of allosperm, selfing becomes the only mode of fertilization and that the turn from cross-fertilization to selfing produce a decrease in fecundity of about $40 \%$. From these previous observations and our results it can be speculated that lymnaeids and planorbids might follow different reproductive strategies, the former giving priority to selffertilization as a way to guarantee the local adaptation to the most suitable habitats with less genetic variability than the latter, which give priority to cross-fertilization as a way to generate diverse genotypes across generations and among offspring to cope with spatial and temporal variability (Jarne $\&$ Stadler 1995).

Further investigations will be performed using snail-conditioned water to test a hypothesis for a possible chemical inhibition of the reproduction and the foraging behavior. A better understanding of this relationship will be useful for further laboratory experiments as well as for the understanding of the snail populations' dynamics in natural conditions.

\section{ACKNOWLEDGEMENTS}

To J Sánchez for his technical assistance, to A Theron and to anonymous reviewers for their valuable comments on the manuscript.

\section{REFERENCES}

DeWitt RM, Sloan WC 1958. The innate capacity for increase in numbers in the pulmonate snail Lymnaea columella. Trans Amer Micr Soc 76: 290-294.

De Visser J, Ter Maat A, Zonneveld C 1994. Energy budgets and reproductive allocation in the simultaneous hermaphrodite pond snail, Lymnaea stagnalis: a trade-off between male and female function. The American Naturalist 144: 861-865. 
Doums C, Delay B, Jarne P 1994. A problem with the stimate of self-fertilization depression in the hermaphrodite freshwater snail Bulinus truncatus: the effect of grouping. Evolution 48: 298-504.

Ferrer JR, Perera G, Yong M, Amador O 1988. Comparación del crecimiento de Fossaria cubensis y Pseudosuccinea columella (Mollusca: Pulmonata: Lymnaeidae), hospederos intermediarios de Fascola hepatica en Cuba. Rev Cub Med Trop 40: 29-35.

Ferrer JR, Perera G, Yong M, Amador O 1989. Life tables of Fossaria cubensis and Pseudosuccinea columella, intermediate hosts of Fasciola hepatica in Cuba. J Of Med \& Appl Mal 1: 189-194.

Hyman LH 1967. The Invertebrates, McGraw-Hill, Inc., $792 \mathrm{pp}$.

Jarne P, Stadler T 1995. Population genetic structure and mating system evolution in freshwater pulmonates. Experientia 51: 482-497.

Kendall MG 1975. Rank Correlation Methods, 4th ed., Griffin, London, 282 pp.

Malek E, Chrosciechowski P 1964. Lymnaea (Pseudosuccinea) columella from Venezuela and notes on distribution of Pseudosuccinea. Nautilus 78: $54-56$

Martínez R, Miranda R 1968. Aspectos de la reproducción en moluscos pulmonados del área metropolitana de Caracas. In Estudio de Caracas. 1. Ecología Vegetal y Fauna, Universidad Central de Venezuela, Caracas.

Mauri M 1981. Duración de la partenogenia de Fasciola hepatica en el molusco Lymnaea columella. (Resúmenes). 1er Congreso de Ciencias Biológicas, La Habana, Cuba, 430 pp.

Morales G, Pino LA, Rodriguez E 1983. Diseño de estrategias de control para poblaciones de Lymnaea cubensis Pfeiffer 1839 y Lymnaea columella Say 1817. Bol Dir Malariol San Amb 23: 11-17.
Morales G, Pino LA, Perdomo L 1986. Utilidad del conocimiento del tamaño del molusco Lymnaea cubensis en la implementación de programas de control de la distomatosis hepática. Rev Fac Cs Vets UCV 33: 22-27.

Morales G, Rodríguez E, Pino LA, Perdomo L 1985. Estadísticas vitales de Lymnaea cubensis (Pfeiffer, 1839) en condiciones de laboratorio. Bol Dir Malariol San Amb 25: 89-99.

Nezlin LP 1997. The osphradium is involved in the control of egg-laying in the pond snail Lymnaea stagnalis. Inv Rep \& Dev 32: 163-166.

Pino LA, Morales G, Rodriguez E, Perdomo L 1986. Crecimiento y alometría de Lymnaea cubensis y Lymnaea columella. Bol Dir Malariol San Amb 26: 50-60.

Sanchez R, Perera G, Sanchez J 1995. Cultivo de Fossaria cubensis (Pfeiffer) (Pulmonata: Lym-naeydae), hospedero intemediario de Fasciola hepatica (Linnaeus) en Cuba. Rev Cub Med Trop 47: 71-73.

Stearns SC 1992. The Evolution of Life Histories, Oxford University Press, $249 \mathrm{pp}$.

Vergani F 1955. Datos biológicos experimentales sobre el caracol Lymnaea cubensis. Bol Inst Inv Vet 23: 34-55.

Vianey-Liaud M 1976. Influence de l'isolement et de la taille sur la fécondité du planorbe Australorbis glabratus (Gastéropode Pulmoné). Bull Biol Fran Bel 110: 5-29.

Vianey-Liaud F 1998. La reproduction chez un mollusque hermaphrodite simultané, la planorbe Biomphalaria glabrata (Say, 1818) (Gastéropode, Pulmoné). Haliotis 27: 67-114.

Yong M, Gutierrez A, Perera G, Sanchez J 1996. Life tables of three populations of Fossaria cubensis (Pulmonata: Lymnaidae) under laboratory conditions. J Med Appl Malacol in press. 
Effect of Isolation on P. columella • Alfredo Gutierrez et al. 